July 2018

\title{
Leave Them to Their Own Devices: Healthcare Students' Experiences of Using a Range of Mobile Devices for Learning.
}

Julie A. Attenborough

City, University of London, j.a.attenborough@city.ac.uk

Stephen Abbott

City, University of London, s.j.abbott@city.ac.uk

Follow this and additional works at: https://digitalcommons.georgiasouthern.edu/ij-sotl

\section{Recommended Citation}

Attenborough, Julie A. and Abbott, Stephen (2018) "Leave Them to Their Own Devices: Healthcare Students' Experiences of Using a Range of Mobile Devices for Learning.," International Journal for the Scholarship of Teaching and Learning: Vol. 12: No. 2, Article 16.

Available at: https://doi.org/10.20429/ijsotl.2018.120216 


\title{
Leave Them to Their Own Devices: Healthcare Students' Experiences of Using a Range of Mobile Devices for Learning.
}

\begin{abstract}
Given recent advances in mobile technologies, there has been a shift from e-learning to mobile learning in UK universities, yet there are few data about how students select and use mobile devices, and whether elearning systems and materials are fully compatible.

Healthcare students have placements in clinical practice where they use mobile devices to access university course information and learning materials.

This study investigated student use of devices in the School of Health Sciences, City University London. Eight final-year students from different disciplines participated: they were issued with a device and reported on how they used it via a personal blog, interviews and focus groups.

Thematic analysis was applied to the data. Two groups of themes were identified: factors relating to the devices themselves (strengths and weaknesses; learning to use them; enjoying them) and to the course (university work; in clinical placement).

Students had similar observations and experiences of the different devices, both at the university and in clinical practice, and this paper reports on their perceptions. The importance of Wi-Fi access, suitable learning spaces and permissions to use devices were important findings, as was evidence of the enjoyment students found in using the devices.
\end{abstract}

\section{Keywords}

mobile learning, healthcare students, mobile devices, personalisation, BYOD

Creative Commons License

cc) (i) $\Theta \Theta$

This work is licensed under a Creative Commons Attribution-Noncommercial-No Derivative Works 4.0 License. 


\title{
Leave Them to Their Own Devices: Healthcare Students' Experiences of Using a Range of Mobile Devices for Learning
}

\author{
Julie A.Attenborough and Stephen Abbott \\ City, University of London
}

(Received I September 2017;Accepted 27 April 2018)

\begin{abstract}
Given recent advances in mobile technologies, there has been a shift from e-learning to mobile learning in UK universities, yet there are few data about how students select and use mobile devices, and whether e-learning systems and materials are fully compatible. Healthcare students have placements in clinical practice where they use mobile devices to access university course information and learning materials. This study investigated student use of devices in the School of Health Sciences, City, University London. Eight final-year students from different disciplines participated: they were issued with a device and reported on how they used it via a personal blog, interviews and focus groups. Thematic analysis was applied to the data.Two groups of themes were identified: factors relating to the devices themselves (strengths and weaknesses; learning to use them; enjoying them) and to the course (university work; in clinical placement). Students had similar observations and experiences of the different devices, both at the university and in clinical practice, and this paper reports on their perceptions. The importance of $\mathrm{Wi}-\mathrm{Fi}$ access, suitable learning spaces and permissions to use devices were important findings, as was evidence of the enjoyment students found in using the devices.
\end{abstract}

\section{INTRODUCTION}

This project investigated the use of eight commonly used mobile devices by students in a School of Health Sciences (SHS) in London. Final year student volunteers from eight healthcare disciplines were randomly allocated a device to use in their personal life, at university and in clinical practice. Students had the freedom to use the device in whichever way they wanted and the study was therefore particularly suited to exploring choices students make about the use of devices (Cochrane and Bateman 2010; Kobus et al 2013; McLoughlin and Lee 2008).

\section{Background}

Mobile technologies have advanced over recent years and the use of social networking tools across the population has greatly increased (Mandula et al 20I3). There has been a corresponding shift from e-learning to mobile learning in UK universities; though e-learning (using a computer or lap-top) may be considered better suited for in-depth studying, the benefit of m-learning is its immediacy, availability and for practitioners its portability for use in clinical practice (Korucu and Alkan, 20I I). With the increasing use of mobile devices among the student population, there is an emerging literature about the application of mobile learning in education and the importance of some of the technical features (Biden and Ziden, 20I3). There is evidence that learning is affected by the tools used and that the design of education has in turn been influenced by available tools, especially those associated with social networking (Ravenscroft et al 20I2).

Traxler (2016) notes the impact of mobile technologies on society and culture and in personal interactions, where smartphones give access to everyday activities and interactions. Traxler also explains the potential to remove barriers to learning with access to using and creating learning materials.

In 20 I4, ownership of mobile devices eclipsed desktop computers and this was expected to increase to a factor of four in 2016, though Hischier and Wager (2015) suggest that consumers are adding devices rather than replacing one with another.

Kobus et al (2013) investigated ownership and on-campus use of mobile devices compared with computer labs and, more specifically, the impact of 'bring your own device' (BYOD) initiatives by universities. They identified a number of reasons why students did and did not bring their devices to university, including comfort in use (for group work), better functionality, crowding in university computer labs, and use while commuting. Students identified the weight of laptops, fear of theft and access to printers as reasons not to bring their device to university. Students were also discouraged by the limited storage capacity of the devices themselves and the consequent necessity to use cloud storage.

Mobile pedagogy includes the potential to increase active learner participation through collaborative and communication tools, to increase learner based content and hence productivity, innovation and original thought and personalisation (Cochrane and Bateman 2010; Kobus et al 2013; McLoughlin and Lee 2008). Though much of the literature focusses on mobile technology as an "add on", there is evidence that this is changing (Cochrane and Bateman 2010). Wu (2014) notes the potential for developing diverse learning methods (e.g. sharing information, online discussion) through the use of mobile learning, demonstrating the advantages of interactivity, speed and enjoyment to nursing students learning with mobile devices. Furthermore, Moodle, a virtual learning environment (VLE) that utilises web2 tools and is designed for socially constructed learning has been adopted widely across UK universities (Costello 20I4). This has further increased the potential for student use of mobile learning. In the case of health care students, mobile devices offer the possibility of having access to online educational materials while undertaking clinical placements in health care settings, with increased opportunities for situated or work-based learning, such as learning in practice (Martin and Ertzberger 2013).

Kearney et al (20I2) provide a pedagogical framework to inform the development of mobile learning. Focussing on the perspective of learners' experiences rather than the technologies, their theoretical perspective is that learning is a situated, social endeavour: this can be facilitated through social interaction, but crucially is mediated through the use of tools. The paper encourages teachers to reflect on their teaching materials and 
techniques and to think about the design of these in the light of mobile learning.

Kearney et al (2012) identify three features of mobile learning: authenticity, collaboration and personalisation. Authenticity refers to the fit between the device itself, the tasks it is required or desired to do, and the context in which it is operated. Collaboration refers to the ways in which students work together and/ or with teaching staff to access, use and discuss data. Personalisation refers to the individual choices students make about how, when and where to use the device.

At the time of the inception of this study, over $75 \%$ of visits to the university's VLE (Moodle) were via a mobile device (Google analytics, accessed $28 / 02 / 13$ ), yet little was known about how students use mobile devices, their choice of device, and the compatibility of university electronic learning systems with different devices. Cochrane and Bateman (2010) in their analysis of mobile learning projects demonstrated that in higher education, the choice of mobile device is affected by functionality (it does what a student needs it to do) and social acceptability to the individual student. Filho and Costa (20I5) suggest that the 'hedonic' (pleasurable) aspects of a device are also an important factor in the choice and use of devices.

In 2005, Childs et al affirmed the potential use of mobile devices to give healthcare students in clinical practice access to learning resources, and they noted the increasing use of mobile devices for diagnostic and administrative functions in the National Health Service. Students studying at the SHS, particularly in their final year, have substantial periods working in clinical practice where they may use mobile devices to access course information, university communications, assessments, learning materials and academic discussion forums. In some clinical placement settings, mobile devices are also used as therapy tools.

In clinical practice, learning contexts are to some extent generated by students. Much of their learning is self-driven, as students agree their learning objectives with their practice supervisors or mentors, and, within the constraints of professionally regulated programmes, negotiate plans to practice or observe relevant clinical and administrative tasks, and to experience encounters with patients. The powerful combination of situated and personalised learning afforded by mobile learning has the potential to narrow or close the gap between the personal and educational aspects of learning (Cochrane 20I4; Traxler 2007).

This study investigated use by healthcare students of a range of currently available tablets and smartphones during the academic year 2013/14.

\section{The research question}

How are selected mobile devices used for learning in the university and in clinical practice; and what are student perceptions of their efficacy and helpfulness to their learning?

\section{AIMS OF THE STUDY}

The aims of the study were:

I. To investigate students' perceptions of the efficacy of currently available devices in accessing electronic learning and assessment tools in the School of Health Sciences and in their clinical placements; and their perception of helpfulness to their learning.
2. To establish the importance of the usefulness (utilitarian) versus hedonic value of mobile learning

\section{METHODS}

All final year undergraduate students in the SHS were e-mailed with an explanation of the project and an invitation to take part. The main reason for asking final year students to participate was that they would all be undertaking clinical placements as well as university-based study.

Seventy-two students volunteered. Random number tables were used to select one student from each of the eight disciplines in the School (adult nursing, child nursing, mental health nursing, midwifery, optometry, diagnostic radiography, therapeutic radiography, and speech and language therapy). The number of participants was restricted to the number of devices available. By chance, these were all female, reflecting the predominance of female students in the school. We chose to include all disciplines in order to capture the broadest range of learning contexts. The disadvantage of this decision in a small sample is that it cannot ensure a variety of individual student approaches to learning and to technology. However, this would have been difficult to do without screening volunteers (by interview or psychometric text), for which resources were not available. We did not ask students to name their first language, but all spoke English fluently and idiomatically.

Devices were allocated at random, although in one case, the student already had a device so similar to the one allocated that an exchange was made.

Students were encouraged to use the device both in their university studies (lectures, seminars, private study, preparation of written assignments) and in their clinical placements, provided that permission from the clinical area was sought and given. All participants were undertaking a combination of academic work and clinical practice placements during the study; including in-patient wards, optometry clinics, schools, community nursing and midwifery, and radiography/radiotherapy departments. Use of the device was reported via personal blogs, individual interviews and two focus groups. Students who completed the study were permitted to keep the device.

It was explained that, by accepting the device, students agreed to contribute to the project as follows:

- $\quad$ attend two focus groups

- attend an individual interview

- contribute to an online blog

The university's educational technology team advised the project team about the choice of devices based on their knowledge of market leaders, popularity with our student population and price.

The focus groups took place near the beginning of the project (November 2013) and just over half way through (February 2014); interviews took place in March and April 20I4. Students were encouraged to blog throughout the project about their experience of using their allocated device, blogs were visible to other participants and the investigators, and informed the focus groups (see topic guide).

Topic guides were developed for the focus groups and interviews, based on current literature and the researchers' own experiences and observations (see Appendices I and 2). All interviews and focus groups were audio-recorded and transcribed, the blogs were downloaded and analysed in the same way as 
the interviews and focus groups.All three authors repeatedly read the material, and then worked together to identify themes and combine them into a coherent thematic framework. The authors looked for material relating directly to the anticipated themes, which underpinned the topic guides, and also for unanticipated themes emerging from the data.

Ethical approval was granted by the SHS Research Ethics Committee. Confidentiality and anonymity were assured, and have been maintained in this paper.

\begin{tabular}{|l|l|l|l|l|l|l|}
\hline \multicolumn{6}{|l|}{ Table I. Students' devices, disciplines, and participation } \\
\hline Code & \multicolumn{1}{|c|}{ Discipline } & \multicolumn{1}{|c|}{ Device } & $\begin{array}{c}\text { Attend } \\
\text { FGI }\end{array}$ & $\begin{array}{c}\text { Attend } \\
\text { FG2 }\end{array}$ & $\begin{array}{c}\text { Attend } \\
\text { interview }\end{array}$ & Blog \\
\hline AN & Adult nursing & Samsung Galaxy Note & Y & Y & Y & Y \\
\hline CN & Child nursing & iPad & Y & Y & Y & Y \\
\hline MN & Mental health nursing & Microsoft Surface & Y & N & Y & Y \\
\hline MI & Midwifery & Kindle Fire 7 inch & Y & N & N & Y \\
\hline ST & Speech and language therapy & Kindle Fire I0 inch & N & N & Y & Y \\
\hline OP & Optometry & Google Asus Nexus 7 & Y & Y & Y & Y* \\
\hline DR & Diagnostic radiography & iPod Touch & Y & Y & Y & Y \\
\hline TR & Therapeutic radiography & iPad Mini & Y & Y & Y & Y \\
\hline
\end{tabular}
Students are identified by their course

\section{Ease of use}

(adult nursing $=\mathrm{AN}$; child nursing $=\mathrm{CN}$; mental health nursing = MN; midwifery = Ml; optometry = OP; diagnostic radiography = DR; therapeutic radiography $=\mathrm{TR}$; and speech and language therapy = ST). In general, what students said in interviews was fully consistent with what they said in focus groups and blogs, and data from all sources have therefore been used freely and indistinguishably.

\section{FINDINGS}

Table I lists the devices, the students' disciplines, and each student's contribution to the data set. Five themes were identified, which can be arranged into two groups:

- Factors relating to the devices: strengths and weaknesses

- Factors relating to the devices: learning to use them

- Factors relating to the devices: enjoying them

- Factors relating to the course: use for university work

- Factors relating to the course: use on clinical placement

\section{Factors relating to the devices: strengths and weaknesses}

The strengths and weaknesses of the devices related to:

- portability

- ease of use

- planning

- web access and software

\section{Portability}

Students valued the portability of devices, particularly when compared with laptops. Most of the devices fitted into a bag or pocket easily, and were light.

Weight is important, because if you are carrying it around, especially if you have books and stuff and you have other things in your bag. (TR)

Portability also increased the opportunities for working:

I'm more likely to do work because the device is portable and with me... it is useful when travelling (CN).

Thus, some students had worked over the Christmas break when staying with relatives. But some did not use their device when on public transport because of concerns about the risk of theft, while another commented that she

would have liked to use it to do some work while I travel around but due to lack of internet connection, it is not possible. (TR)

Being small enough to carry easily had its disadvantages, though. In particular, the small screen meant that writing on the device was difficult.

It's not great for writing, for which a laptop is more comfortable... a conventional keyboard is better, but this device doesn't have one. (OP)

Another had bought a keyboard to use, though she did not find it satisfactory.

it would be good to be able to type Word documents on to it (ST)

Though most participants found writing difficult although possible, two had used the device extensively for writing. Others commented that even small devices were useful for making brief notes:

[it is] handy to make notes quickly if [a] light bulb comes on at [an] inconvenient moment. (CN)

One student used voice recognition software on her device when drafting documents.

Two students found devices with small screens difficult to use as a reading tool, describing how they had to keep swiping or scrolling down in order to read each page of an e-book.

\section{Planning}

Some of the students found the device particularly useful as a planning tool.

It has been really good for just basic organisation because I am really unorganised... especially to have it synched up to your Google calendar... being able to type little queries... What is the next lesson? Or, what module is this part of? (DR)

Another found it useful when planning her day, for example, to check library opening hours. One talked of how planning with her device encouraged concentration:

I find it easier to keep everything in one place as well... if I had bits of paper, they would be everywhere. It makes me feel more organised, it makes me feel more in control of my work and more sort of like my brain knows what is going on... if I have got a million things to do, I can't concentrate on my work, because I am thinking, What was it I needed to do? (CN)

Another had found

an app that tracks how much you're studying. It's quite self-motivating, to see where I am wasting my time, not studying. (AN) 


\section{Web access and software}

Several students found it difficult to fully access university websites using their devices, in particular timetables and the VLE. Some also had problems with particular packages, such as PDFs or PowerPoint. One found that her device reformatted Word documents, which then needed re-editing on a desk-top computer, while others found it impossible to store documents that they had been working on. (It is of course possible that these experiences reflected the limitations of their own skills rather than those of the devices).

\section{Factors relating to the devices: usage} Learning to use them

Students appeared to learn how to use the devices fairly quickly, and, generally speaking, appeared to be confident and competent by the first focus group. This was not universal, though: for example, AN said in the first focus group that

I am finding it very difficult...'

But she gave more positive reports later:

It was fairly easy to learn to use it: having to learn on the spot and seeing what you can do and what seems to go wrong ' (AN)

Other students drew on existing expertise:

'I've used a similar product before.... My Dad has an iPad, I have an iPhone. (OP)

Those learning from scratch did not always find it easy initially.

There was only a very short and basic tutorial right at the beginning when I first switched it on, and ever since then I have to figure it out myself or go on the internet and search.... It is quite difficult to get to know it... quite frustrating... hard to figure out little essential things. (MN)

I found a YouTube video on how to use it. It was overwhelming at first, then it was easy. (MI)

\section{Enjoyment}

Participants explained how, once a degree of competence had been achieved, use of the devices brought pleasure and enjoyment.

It's nice when you can use a device for both work and fun.... you actually have to have an interest in the device to use it. (MI)

In particular, the pleasure increased motivation:

It has definitely motivated me because when I got it I was quite excited to use it. (OP)

It's kind of exciting to have the iPad and so I think "I will sit down and do this". Not sort of ... "I have got to do it, and it's boring." (CN)

Some students spoke of the devices in terms implying intimacy. A sense of attachment was evident from early on in the study ("my new love affair" (MN)). Another said:

My boyfriend says he can't believe I would be so lost without it. Yes, it is coming between us! (DR)

She later made some criticisms of the device, and then added:

I was going to say something to "big up my little guy!" Feel a bit bad for slagging him off? (DR)
But she found using the device so enjoyable that she felt in some ways 'taken over' by the brand:

So now I find that I am a bit "Apple"... I do think that is the down point of the Apple devices. But at the same time, they make you feel very comfortable with it, because actually all of their Apps and things are really good and they work really well ... But at the same time it is a little bit pervy! (DR)

\section{Factors relating to the course: use for university work}

Students identified a range of uses:

- access to information

- access to apps

- use in revision

\section{Access to information}

Many comments related to the flexibility of the devices in academic study, including the advantages of portability set out above. One participant commented that the device could be used in the library if a desktop computer was not available.

Six students commented that the device enabled them to look information up quickly: for example, accessing databases, lecture slides and notes.

I have used the kindle a lot to access the library and databases and eBooks for my dissertation. Have downloaded several textbooks from Amazon, which are far cheaper than hard copies and a lot easier to carry around and be able to access anywhere! (MI)

However, one person's device was less useful for accessing articles than for slides and notes, because of screen size.

Some used the device to have lecture notes open during lectures, to make notes and/or to be able to look up information that would aid understanding as the lecture continued.

One, (OP) recorded lectures and listened to them again later, and used the camera on her device to photograph her friend's notes if she missed a lecture. Another reported using her device in group work:

We've also been preparing a media article and presentation, and it's been useful to pull up information whilst were sitting in our seminars or group meetings to save us having to traipse up three floors to a computer room! (CN)

Students tended to be most pleased with their devices as learning aids when they used them alongside a desktop or laptop. All participants appreciated the fact that the devices synched with their laptop and/or desktop.

Typically, they used the mobile device to access journal articles for consultation while working on their dissertation on something larger. One used the device to consult assessment guidelines when writing an essay.Another (not identified for confidentiality reasons) explained:

Being dyslexic it makes it hard for me to flick between things and work out where things are on the page, and follow, and so it is easier for me to have it there and I can keep on the same line on my laptop...

This helped to motivate her to get on with her work instead of procrastinating.

It was much less common that students reported using their device to create academic work: 
I am really enjoying how quick and easy it is to create and read word documents, spreadsheets and PowerPoint presentations and upload them to the cloud to access anywhere too! (MI)

The infrequency of this view probably reflects the difficulties of use already noted.

\section{Access to apps}

Four students commented on the ease with which different apps could be downloaded to support their learning. Some of the apps mentioned included supernote pro for quick notes, eBooks, an anatomy app, puzzles, first aid manual, medical abbreviations, word processor, using Siri to search, and the British National Formulary. However, one had found it hard to find educational apps, and when she did, they were costly.

\section{Use in revision}

Some students commented on the usefulness of the device during revision. One alluded to the fact she could revise on a train (anytime, anywhere). Two found their devices made watching videos for revision purposes easier. One commented that she recorded herself reading revision notes aloud and played them while she was going to sleep, while another welcomed the fact that

It makes creating and using revision materials so much easier and more efficient. (MI)

\section{Use on clinical placement}

One student found her device

...really wonderful to use on placement. So instead of like printing off my portfolio of activities, I have just been able to get the tablet out and sit with my mentor and go through it. (AN)

It was

easy to look up anything if there is a spare 10 minutes. (TR)

One student said that being connected with the university through the VLE as and when she wanted made her feel supported whilst on clinical placement. .

However, others experienced difficulties in using their devices in the clinical area because of internet connections and firewalls which prevented them from accessing, for example, the university VLE. This was especially true for radiotherapy students where there is special shielding to protect students from radiation. Lack of access to Wi-Fi was an issue for some students.

The iPod is not particularly useful on placement ... hospitals do not generally provide Wi-Fi, but I hope to make it more useful by downloading material to watch/read/listen to when offline (DR)

In some clinical placements, the use of internet-enabled devices is prohibited. Their use on placement was also determined by the approach of the clinical educator or supervisor. While some supervisors extolled the use of devices, others felt less positive about them, worrying that devices might distract, be dropped, or constitute an infection hazard.

It's a shame l've not been able to take the iPad in to placement, as I'm currently in neonatal intensive care, and there is loads of stuff that's new to me and would be useful to be able to easily look up during my shift. (CN)

One student who was not allowed to use her device actively for the delivery of therapy did find it was useful for keeping the session plan in front of her instead of printing it out (ST).
One student with an android device was concerned that the range of apps available might not be sufficient for her clinical placement.

Using the device clinically may work, although finding a suitable app to use with my year I children in the school of the deaf may pose as a problem as I find Amazon apps to be limited. (ST)

\section{DISCUSSION}

With regard to the aims of the study, the findings can be summarised thus:

I. Student participants in the study generally perceived currently available electronic devices to be useful in assisting learning both in accessing university learning tools and in their clinical placements. There was variance in how participants used their devices, reflecting not only individual preferences, but also the opportunities and limitations of both the devices and their learning contexts.

2. Though all students based their judgements primarily on usefulness, some expressed very positively the hedonic value of mobile learning.

It is striking that in this small sample of different devices and disciplines, students had similar observations and experiences of the efficacy of currently available devices in accessing electronic learning at the university. All of the students had explored their devices' capacity to link to and enhance their educational experience. Interestingly, we did not find any evidence of significant difference between students that reflected the technical differences between their devices. For example, though students talked about the advantages and drawbacks of different devices, the overriding comments were about portability versus the size of the screen, rather than anything more technical.

\section{Potential of devices to enhance learning}

Clearly students saw the potential of the devices and found that, where their use was not prohibited either by practice placement rules or lack of internet access, they enhanced their learning. The use of the devices at the university, where computer lab space on campus was either unavailable or inconvenient is consistent with the decision of some universities to move towards a Bring Your Own Device (BYOD) approach (Kobus et al 2013). Robust $\mathrm{Wi}-\mathrm{Fi}$ and a commitment to maintain it are crucial to the success of BYOD and the idea of any space being a learning space (Cochrane and Bateman, 20I0). Equally important is the provision of spaces at university for students to use their devices.

Students commented that materials such as timetables and educational materials on the VLE were not easily accessed using their devices. This has also been reported in the mobile learning literature (Hameed and Shah 2009), and illustrates a theme in other studies; where mobile learning is student driven, but the implementation of university technologies, predominantly delivered by a VLE is not (Gikas and Grant 2013;Viberg and Gronlund 20I5) The importance of a university strategy to include investment and student input, staff training and awareness of mobile learning is therefore very important to ensure that students can draw maximum benefit from using mobile devices in their studies. Chen and Devolles (2013) suggest professional development to help lecturers to integrate mobile technologies into their curricula, along with listing frequently-used academic apps 
to assist incorporation. Polling students in advance of using apps to establish compatibility, an awareness of students who do not own devices and establishing a loan system are also suggested in this paper, which documents a study of I,082 students.

The evidence of hedonic value that we found suggests that there is real potential for educators to improve engagement with learning. The excitement students expressed about using their device and the joy they described in discovering both academic and personal uses was sometimes more vivid than what they reported about the devices' usefulness. This could be seen most clearly with Apple products, whose potential to engage and excite students compared to desk top computers has been demonstrated elsewhere (Martin and Ertzberger 2013). The potential to support learning by capitalising on the hedonic value of the devices can be increased by the design of learning activities and materials suitable for mobile devices (Chen and Denoyelles 2013). Furthermore, the importance of social media and its potential to transform learning is associated with the hedonic experience of device use (Parsons 2013). By integrating social media into learning activity (both in clinical practice and in classroom-based education), there is potential for barriers to learning to be overcome.

\section{Use of devices in clinical placements}

Constraints for using the devices in clinical placement were significant, but these may disappear over time with increasing use of mobile devices in clinical practice and the changing demographic of qualified staff and supervisors in practice. For the purposes of this study, mobile learning in placements was problematic, but students did appreciate being able to load materials on to their devices rather than having to carry large textbooks around. This was also found to be an advantage by Wu (20l4). Participants also commented on the usefulness of being able to use the devices to incorporate learning into their daily routines, such as when travelling to placements. The time economy in students' self-initiated study afforded by mobile devices is also reported by Viberg and Groland (2015) in a study of mobile device use by language students. The paper suggests that this preference should be a consideration for course design, with short tasks and frequent feedback mechanisms.

There was clear evidence of situated learning in some participants, who used their device to access up-to-date materials when they had queries, and this has been demonstrated elsewhere in the literature (Gikas and Grant 2013; Martin and Ertzberger 2013).

\section{Authenticity and personalisation}

These findings usefully illustrate two of Kearney et al's (20I2) three characteristics of mobile learning, authenticity and personalisation. The choices students made about how to use their devices (personalisation) were strongly influenced by matters of authenticity (the fit, or lack of it, between the device, the task and the environment). Instances of lack of fit were often outside of the student's control, such as $\mathrm{Wi}-\mathrm{Fi}$ access and permissions. Collaboration is the third aspect of mobile learning. The design of the project precluded the gathering of data about collaboration, as each participant studied a different discipline. Although a Moodle space was set up with the possibility of synchronous and asynchronous discussion as part of the project, there was little engagement, apart from individual blogging, which was a require- ment of the study. Some intra-discipline collaborative work was mentioned, such as online preparation for group presentations. Sharing of knowledge about the devices, including demonstrating different functions took place in the face-to-face focus groups.

The use of mobile devices for academic work may be device specific (Chen and Denoyelles 2013), and this in turn may be related to income, with lower-income students tending to use smaller devices and not to use these as extensively for academic purposes as those with larger devices such as tablets. In this study the device used did not correlate with income, but did have a similar effect on use for academic work.

Affordability and equitable access were not specifically explored in the project, but are important to consider. The affordability of mobile devices must vary depending on student income. Participants did refer to having had to struggle with the most basic of devices previously due to income constraints. Although Kobus et al (2009) found only a weak correlation between the income of students and device ownership, the number of students volunteering for this project, which was far in excess of normal rates of such volunteering, may suggest that students cannot easily afford to purchase mobile devices.

\section{Importance and implications of the findings}

- The portability, acceptability and flexibility of mobile devices has considerable potential for use in the education of healthcare students, enabling them to maximise their time, and benefit from situated learning.

- Mobile devices enable students to keep in touch with their university and with their peers when in clinical placement, minimising isolation.

- The widespread use of mobile devices among the student population has implications for the design of learning activities and the on-line provision of university facilities, such as libraries and timetables.

- Design of learning activities for mobile devices must have student input to ensure compatibility with operating systems and usability.

\section{Limitations of the study}

The generalisability of our findings is limited to some degree by the inclusion of devices that are no longer the most up-to-date available. Also, the small sample limits generalisability, as does its restriction to some health care disciplines. Though it is reasonable to assume that the experiences reported here are widespread, we cannot claim that our study is in any way exhaustive. More and larger studies with similar aims and design but studying a greater variety of student populations would help to create a more robust knowledge base. It would also be useful to study collaboration, which we were not able to do. Such data would assist educators in ensuring that learning materials have optimum fit with the habits and preferences of their students. At the time of the study few students owned smart phones, including those who participated. This has clearly changed, though the availability of advanced devices may be out of reach of most healthcare students.

The study focussed on the perceptions of students, and no other measures were used to access efficacy of devices for learning. 


\section{CONCLUSION}

Our study demonstrates that healthcare students are able to use a range of mobile devices in their studies and in a number of ways; suggesting that students find the use of mobile devices a convenient and pleasurable addition to their repertoire of study techniques. Attachment to the device itself was evident in some participants who demonstrated the importance of the hedonic value of mobile learning.

Despite drawbacks relating to the devices themselves and the environment, all participants were able to develop personal ways of using the devices to enhance their studies, and problems were often attributable to either the skills of the participant, internet access or to the compatibility of university systems. However, the cost of purchasing mobile devices needs to be taken seriously by educationists, given the low incomes of many students. Higher education institutions need to be committed to maximising the potential for such devices to promote student learning by providing access and study spaces at university, encouraging clinical placements to support their use, and creating appropriate educational materials and tasks.

\section{ACKNOWLEDGEMENTS}

Although two authors are listed for this paper, a third researcher, Roberta Williams, participated in the project but passed away while the manuscript was being written. Julie Attenborough and Stephen Abbott gratefully acknowledge her significant contributions to the project and this paper.

\section{REFERENCES}

Bidin, S. and Ziden,A.A., 20I3.Adoption and application of mobile learning in the education industry. Procedia-Social and Behavioral Sciences 90, pp.720-729.

Chen, B. and Denoyelles, A., 2013. Exploring students' mobile learning practices in higher education. Educause Review. Retrieved from http://www. educause. edu/ero/article/exploring-students-mobile-learning-practices-higher-education.

Childs, S., Blenkinsopp, E., Hall, A. and Walton, G., 2005. Effective e-learning for health professionals and students-barriers and their solutions: A systematic review of the literaturefindings from the HeXL project. Health Information \& Libraries Journal, 22(s2), pp.20-32.

Cochrane, T.D., 2014. Critical success factors for transforming pedagogy with mobile Web 2.0. British Journal of Educational Technology, 45(I), pp.65-82.

Cochrane, T. and Bateman, R., 2010. Smartphones give you wings: Pedagogical affordances of mobile Web 2.0. Australasian Journal of Educational Technology, 26(I) Pp I- 14

Costello, E., 2014. Opening up to open source: looking at how Moodle was adopted in higher education. Open Learning:The Journal of Open, Distance and eLearning, 28(3) Pp. 187-200. doi: | 0.1080/026805|3.20|3.856289

Filho, E.J.M.A. and Costa, E.M.S.D., 2015. Perceptions of hedonic and utilitarian values in consumer choice based on use and future adoption of technological products and innovations. International Journal of Innovation and Learning, I8(4), pp.397412 .

Gikas, J. and Grant, M.M., 20I3. Mobile computing devices in higher education: Student perspectives on learning with cellphones, smartphones \& social media. The Internet and Higher Education, 19, pp. $18-26$.
Hameed, K. and Shah, H., 2009. Mobile learning in higher education: Adoption and discussion criteria. In IADIS International Conference on Mobile Learning (pp. 26-28). Cancun, Mexico. Conferencing Publishing Services

Hatzipanagos, S. and Conole, G. (2012), Designing and evaluating social media for learning: shaping social networking into social learning. Journal of Computer Assisted Learning, 28: I77I82. doi: I0. I I I /j. I365-2729.2012.00484.

Hischier, R. and Wäger, P.A., 20I5. The Transition from Desktop Computers to Tablets:A Model for Increasing Resource Efficiency? In ICT Innovations for Sustainability (pp. 243-256). New York. Springer International Publishing.

Kearney, M., Schuck, S., Burden, K. and Aubusson, P., 20I2.Viewing mobile learning from a pedagogical perspective. Research in Learning Technology, 20, 14406.

Kobus, M.B., Rietveld, P. and Van Ommeren, J.N., 20I 3. Ownership versus on-campus use of mobile IT devices by university students. Computers \& Education, 68, pp.29-4I.

Korucu,A.T. and Alkan, A., 20I I. Differences between m-learning (mobile learning) and e-learning, basic terminology and usage of m-learning in education. Procedia-Social and Behavioral Sciences, 15, pp.1925-1930.

Mandula, K., Meday, S.R., Muralidharan, V. and Parupalli, R., 20I3, January. A student centric approach for mobile learning video content development and instruction design. In Advanced Communication Technology (ICACT), 2013 15th International Conference (pp. 386-390). PyeongChang, South Korea

Martin, F. and Ertzberger, J., 20I3. Here and now mobile learning:An experimental study on the use of mobile technology. Computers \& Education, 68, pp.76-85.

McLoughlin, C. and Lee, M.J., 2008. The Three P's of Pedagogy for the Networked Society: Personalization, Participation, and Productivity. International Journal of Teaching and Learning in Higher Education, 20(I), pp. 10-27.

Parsons, D., 20I3. Jam today-embedding BYOD into classroom practice. QScience Proceedings, (I 2th World Conference on Mobile and Contextual Learning [mLearn 2013), p.25.

Ravenscroft, A., Warburton, S., Hatzipanagos, S. and Conole, G., 2012. Designing and evaluating social media for learning: shaping social networking into social learning?. Journal of Computer Assisted Learning, 28(3), pp. I77- 182.

Taylor, J.D., Dearnley, C.A., Laxton, J.C., Coates, C.A., Treasure-Jones, T., Campbell, R. and Hall, I., 20I0. Developing a mobile learning solution for health and social care practice. Distance Education, 3 I (2), pp. I 75- 192.

Traxler, J., 2007. Defining, discussing and evaluating mobile learning:The moving finger writes and having writ.... The International Review of Research in Open and Distributed Learning, 8(2), pp. I-I 2.

Traxler, J., 2016. Inclusion in an age of mobility. Research in Learning Technology, 24(I), p.31 372.

Viberg, O. and Grönlund, Å. 20 I5. Understanding students' learning practices: challenges for design and integration of mobile technology into distance education. Learning, Media and Technology, Pp. I-2I.

Wu, T.T., 2014. Using smart mobile devices in social-network-based health education practice: A learning behaviour analysis. Nurse Education Today, 34(6), pp.958-963. 


\section{Appendix 1. Focus Group Topic Guides}

Focus Group 1

emboldened text links to aims of the study

Introductions: name, professional area, device

Experience of and pleasure in using mobile devices in general. Aims I and 2

How do you think you will use the mobile device in relation to your university course? Aim I

What experience have you had of using a mobile device in a learning situation? Aim I

What are your hopes and expectations of using your device? Aims I and 2

How connected (electronically) to the university do you feel? Aim I

Probes:

- Anticipated ease of use Aim I

- Connectedness/isolation in placement? Aim I

- Specific devices previously used Aim I

- Anticipated barriers Aims I and 2

\section{Focus Group 2}

How are you getting on? Aim I

What are the high points? Aims I and 2

What difficulties have you experienced? Aim I

Probes:

- Functionality of device Aim I

- Whether device does what you wanted it to do/what did you want it to do/was it easy? Aim I

- What might another device do/what would you like a device to be able to do? Aim I

- Could you get the apps that you wanted, did they work, and how many did you have to use to choose the best? Aims I and 2

- Has there been a cost?

- What are you most using it for? Aims I and 2

- How does it compare with what you were using before for your course (mobile phone, computer, nothing)?

- Connectedness to the university? Aim I

Include any additional areas raised in blogs 


\section{Appendix 2. Interview Topic Guide}

\section{Devices project: individual interviews}

I. When you think about how you use the device, would you say that the most important thing to you is that it is useful, or that it is enjoyable to use it? Does this affect what you use it for? And does it affect how you have or have not used it for learning? Aims I and 2

2. Did it take long to become familiar with the device? Was it frustrating/enjoyable? How do you think someone who isn't as interested in mobile devices as you are would get on? Aim I

3. Has it been easy to incorporate the device into the way you learn? Aim I

4. Have you noticed any behaviour change such as printing less, using Moodle more/less, participating in the interactive aspects of online learning more/less? Aims I and 2

5. Have you noticed feeling more/less motivated about any aspects of learning since using the device? Aims I and $\mathbf{2}$

6. Have you felt more connected with the university? And is this good (convenient) or bad (invasive)? Aim I

7. In what ways might the university change its educational methods to facilitate mobile learning? Is there anything the university could do to enable mobile devices to be more useful? Aim I

8. If there was anything you could add, what would it be (no holds barred!)? Aims I and 2

9. Would you have preferred a different device and if so, which and why?

10. At the end of the project, will you keep your device? 